Original Research Article

\title{
Study of drug utilization pattern and adverse drug reactions of psychotropic drugs in psychiatric inpatient department of tertiary care hospital
}

\author{
Aruna Gurung ${ }^{1 *}$, Jugalkishore B. Jaju², Ganesh R. Pawar ${ }^{2}$, Shrikant C. Dharmadhikari², \\ Rajvardhan R. Solunke ${ }^{3}$
}

\begin{abstract}
${ }^{1}$ Department of Pharmacology, Dr. VM Government Medical College, Solapur, Maharashtra, India

${ }^{2}$ Department of Pharmacology, Government Medical College, Latur, Maharashtra, India ${ }^{3}$ Department of Casualty, Yashwantrao Chavan Memorial Hospital, Pimpri Pune, Maharashtra, India
\end{abstract}

Received: 04 November 2017 Accepted: 27 November 2017

*Correspondence to:

Dr. Aruna Gurung,

Email: arunagurung11@

yahoo.co.in

Copyright: (C) the author(s), publisher and licensee Medip Academy. This is an openaccess article distributed under the terms of the Creative Commons Attribution NonCommercial License, which permits unrestricted noncommercial use, distribution, and reproduction in any medium, provided the original work is properly cited.

\begin{abstract}
Background: Mental disorders are now widely recognized as a major contributor to the global burden of disease. The drug use in psychiatric illness is a complex process and because of this the optimal benefits of drug therapy in patient care is not achieved. This often leads to increased cost of medical care, drug resistance, adverse effects and patient mortality. Hence, this study is undertaken to study the drug utilization pattern and adverse drug reactions of psychotropic drugs in psychiatric inpatient department of a tertiary care hospital.

Methods: A prospective, observational study was undertaken from 1st February 2015 to 31 st July 2016. A total of 250 prescriptions were analysed. Defined daily dose of the drugs were calculated. ADR's were recorded in the format of the National Pharmacovigilance Programme of India (PvPI).

Results: In 250 prescriptions most, common drug prescribed was antipsychotics $(48.5 \%)$. Total drug utilization in terms of DDD/100 bed days was 669 . The total number of adverse drug reactions observed was $8 \%$. Antipsychotics were the most common class of psychotropic drugs causing ADR's.

Conclusions: In conclusion, it has been found that the psychotropic drugs used in our psychiatry department was rational and was based on clinical knowledge, expertise and the guidelines available in the field of psychiatric practice.
\end{abstract}

Keywords: Adverse drug reactions, Drug utilization pattern, Psychotropic drugs, Psychiatric inpatient

\section{INTRODUCTION}

According to recent world health organization (WHO) estimates, nearly one-third of all years lived with disability (YLDs) worldwide can be attributed to neuropsychiatric conditions. ${ }^{1}$ Even though psychiatric disorders are very common the treatment gap is large and is associated with high level of health service utilization and costs. Due to this, their utilization in actual clinical practice, effectiveness and safety in the real-life situations needs continuous study. ${ }^{2}$ 
Hence in recent years studies on drug utilization have become a potential tool to be used in the evaluation of health systems. In psychiatric practice irrational prescribing and polypharmacy is very common. Hence, study on drug utilization research paves a way for better utilization of psychotropic drugs and puts a check on polypharmacy. ${ }^{3}$

Though psychotropic drugs are increasingly being prescribed in clinical practice, these drugs are notorious in causing a number of adverse drug reactions which are frequently fatal and often underreported. Pharmacovigilance in psychiatric unit plays a vital role to ensure therapeutic safety by detecting early alarming signals to estimate risk or benefit of drug profile. ${ }^{4}$

In the light of above discussions, this study is being undertaken to study the drug utilization pattern and adverse drug reactions of psychotropic drugs in psychiatric inpatient department of a tertiary care hospital.

\section{METHODS}

A prospective, observational study was undertaken from $1^{\text {st }}$ February 2015 to $31^{\text {st }}$ July 2016 at the department of Pharmacology and Psychiatry of a tertiary care hospital. Total patients admitted in the psychiatry ward during the study period were included.

\section{Inclusion criteria}

- Patient diagnosed with psychiatric disorder and receiving treatment in the psychiatry ward.

- Patient or patient's relatives who have given informed consent

- Patient with adverse drug reactions to psychotropic drugs

\section{Exclusion criteria}

- Outdoor psychiatric patients

- Patient suffering from epilepsy, drug induced psychosis, alcohol dependence and poisoning cases.

- Patient with co-morbid medical illness

- Patient with adverse drug reactions due to overdose

\section{Data collection}

The relevant data were collected in person by the investigator from the daily case record of the patients. The data were collected in a specially designed proforma which included the following details.

\section{Demographic data}

Represents the Name, age, gender, address, date of admission and date of discharge. For calculating the length of stay, both the day of admission and that of discharge were included.

\section{Disease data}

The diagnosis written in the patient's case sheet were noted along with clinical features, past history of similar illness, family history of mental illness and concomitant illness.

\section{Data pertaining to the treatment included}

Drugs prescribed (with group/class), dose, duration, frequency, change in dose or frequency if any and route of administration.

Cost per tablet, whether purchased from private pharmacy or supplied by hospital and fixed dose combination (if any). The average numbers of drugs prescribed per encounter were calculated to measure the degree of polypharmacy.

Cost per tablets for medicine were derived from hospital rate contract and CIMS (January to April 2015). The costs of the drugs were calculated as price per tablet/ capsules/ injection. Drugs were classified according to the ATC/DDD classification and defined daily dose of the drugs were calculated by using the following formula.

\section{$\mathrm{DDD} / 100$ bed days $=$}

Total dose in mg during study period X 100 DDD of drug X study duration (days) $\mathrm{X}$ bed strength $\mathrm{X}$ average bed occupancy rate. ${ }^{5}$

In present psychiatry ward the occupancy rate was $28 \%$ and bed strength was 40 .

\section{Data pertaining to $A D R$}

Adverse event history, history of medication suspected of causing the ADR and details of concomitant medication used were recorded in the format of the National Pharmacovigilance Programme of India (PvPI).

Assessment of ADR's were done by Naranjos causality scale, Hartwig's severity assessment scale and Schumock and Thornton preventability scale. ${ }^{6}$

\section{Data analysis}

The overall data collected in the specially prepared proforma. Data was entered into Microsoft Excel spreadsheet (version 2013) and analysed using Microsoft Excel and represented as number and percentage.

\section{RESULTS}

A total of 250 prescriptions of the patients who were admitted in psychiatry ward of our tertiary care hospital during the study period of 18 months, based on inclusion and exclusion criteria specified, were studied. 
Of the total 250 patients, $136(54.4 \%)$ were males and 114 $(45.6 \%)$ were females. Highest number of patients (both males and females included) was in the age group of 20-29 years [79 patients $(31.6 \%)]$.

The most common diagnosis among both male and female was schizophrenia. The relative distribution of different psychiatric disorders in both the genders (Table 1).

\section{Drugs prescribed}

A total number of 1143 psychotropic drugs were prescribed. Majority of patients received 4 drugs (66 patients, 26.4\%) followed by 3 drugs (55 patients, 22\%). Average number of drugs prescribed per patient is 4.6.

Table 1: Disease profile of the patients.

\begin{tabular}{|lllll|}
\hline Diagnosis & $\begin{array}{l}\text { ICD-10/ DSM } \\
\text { categories }\end{array}$ & $\begin{array}{l}\text { Male (\%) } \\
(\mathbf{n = 1 3 6})\end{array}$ & $\begin{array}{l}\text { Female (\%) } \\
(\mathbf{n = 1 1 4})\end{array}$ & $\begin{array}{l}\text { Total (\%) } \\
(\mathbf{n = 2 5 0})\end{array}$ \\
\hline Schizophrenia & F20.0-20.9 & $81(59.6)$ & $47(41.2)$ & $128(51.2)$ \\
\hline Brief psychotic disorder & F23 & $14(10.3)$ & $17(14.9)$ & $31(12.4)$ \\
\hline Unspecified nonorganic psychosis & F29 & $11(8.1)$ & $15(13.2)$ & $26(10.4)$ \\
\hline BPAD & F31 & $13(9.6)$ & $08(7)$ & $21(8.4)$ \\
\hline Depression & F32.0-33.9 & $03(2.2)$ & $11(9.7)$ & $14(5.6)$ \\
\hline Schizophreniform disorder & F23.2 & $04(3)$ & $05(4.4)$ & $09(3.6)$ \\
\hline Conversion disorder & F44.9 & $01(0.7)$ & $07(6.1)$ & $08(3.2)$ \\
\hline Schizoaffective disorder & F25.0-25.9 & $05(3.6)$ & $01(0.9)$ & $06(2.4)$ \\
\hline Postpartum psychosis & F53 & $00(0)$ & $03(2.6)$ & $03(1.2)$ \\
\hline OCD & F42 & $02(1.5)$ & $00(0)$ & $02(0.8)$ \\
\hline Acute confusional state & F05 & $01(0.7)$ & $00(0)$ & $01(0.4)$ \\
\hline Delusional disorder & F22 & $01(0.7)$ & $00(0)$ & $01(0.4)$ \\
\hline
\end{tabular}

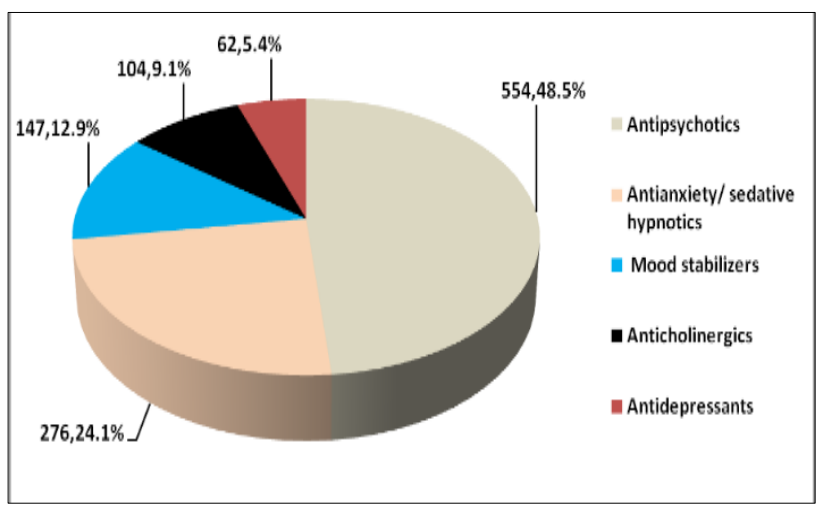

Figure 1: Distribution of psychotropic drugs prescribed by class.

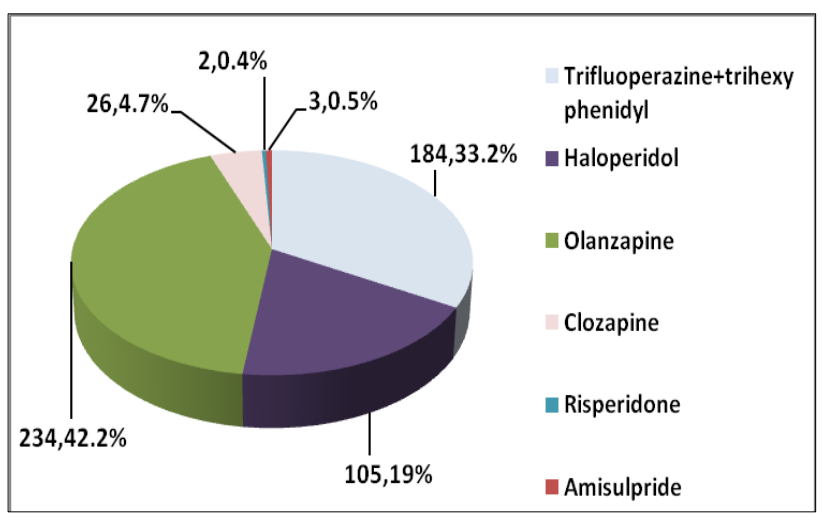

Figure 2: Distribution of antipsychotic drugs usage.
Table 2: Frequency of mood stabilizers drug usage.

\begin{tabular}{|ll|}
\hline Mood stabilizers & Frequency $(\%)(n=147)$ \\
\hline Sodium valproate & $141(95.9)$ \\
\hline Carbamazepine & $05(3.4)$ \\
\hline Lithium & $01(0.7)$ \\
\hline
\end{tabular}

Table 3: Frequency of antidepressant drug usage.

\begin{tabular}{|ll|}
\hline Antidepressant & Frequency $(\%)(\mathbf{n = 6 2 )}$ \\
\hline Tricyclic antidepressants & \\
\hline Amitriptyline & $28(45.2)$ \\
\hline Clomiparamine & $2(3.2)$ \\
\hline Dothiepin & $1(1.6)$ \\
\hline Opipramol & $2(3.2)$ \\
\hline Total & $33(53.2)$ \\
\hline SSRIs & \\
\hline Escitalopram & $23(37.1)$ \\
\hline Fluoxetine & $04(6.5)$ \\
\hline Total & $27(43.5)$ \\
\hline SNRIs & \\
\hline Desvenlafaxine & $01(1.6)$ \\
\hline Duloxetine & $01(1.6)$ \\
\hline Total & $2(3.2)$ \\
\hline
\end{tabular}

The most common class of drug prescribed was antipsychotics $(47.8 \%)$ followed by antianxiety/sedative hypnotics (Figure 1, 2, 3). 


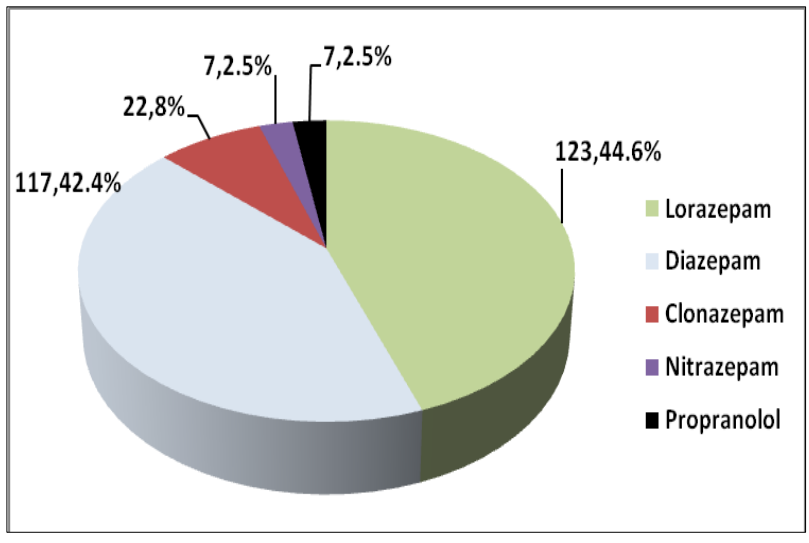

Figure 3: Distribution of antianxiety/hypnotics drug usage.
Other class of drug prescribed were mood stabilizers anticholinergics and antidepressants (Table 2,3).

Amongst antipsychotics olanzapine was most common drug prescribed; amongst antianxiety lorazepam was the most commonly prescribed drug. Trihexyphenidyl plus trifluoperazine combinations were the most commonly used fixed dose combination.

There was a total of 40 beds in the psychiatry ward and the average occupancy index was $28 \%$. Total drug utilization in the psychiatry ward during the study period in terms of DDD/100 bed days was 669. The PDD/DDD ratio for almost all the drugs is $>1$ which indicate adequate dosing except for lorazepam and clonazepam which are showing under dosing as their PDD/DDD ratio is <1 (Table 4).

Table 4: ATC/DDD classification with calculated DDD/100 bed days, PDD values of prescribed psychotropic drugs and PDD/DDD ratio.

\begin{tabular}{|c|c|c|c|c|c|}
\hline Drug & ATC code & DDD (mg) & DDD/100 bed days (mg) & PDD (mg) & PDD/DDD \\
\hline \multicolumn{6}{|l|}{ Antipsychotics } \\
\hline Clozapine & N05AH02 & 300 & 08 & 1388 & 4.6 \\
\hline Olanzapine & N05AH03 & 10 & 418 & 201 & 20.1 \\
\hline Haloperidol & N05AD01 & 08 & 10 & 50 & 6.3 \\
\hline Amisulpride & N05AL05 & 40 & 08 & 1667 & 22.2 \\
\hline Risperidone & N05AX08 & 05 & 0.7 & 33 & 6.6 \\
\hline Total & & 363 & 444.7 & 3339 & 59.8 \\
\hline \multicolumn{6}{|l|}{ Antidepressants } \\
\hline Amitriptyline & N06AA09 & 75 & 8.9 & 826 & 11 \\
\hline Fluoxetine & N06AB03 & 20 & 09 & 480 & 24 \\
\hline Escitalopram & N06AB10 & 10 & 29 & 147 & 14.7 \\
\hline Duloxetine & N06AX21 & 60 & 0.4 & 80 & 1.3 \\
\hline Clomipramine & N06AA04 & 100 & 1.9 & 200 & 02 \\
\hline Opipramol & N06AA05 & 15 & 4.8 & 250 & 16.7 \\
\hline Total & & 280 & 54 & 1983 & 69.7 \\
\hline \multicolumn{6}{|l|}{ Mood stabilizers } \\
\hline Sodium valproate & N03AG01 & 150 & 67.8 & 8290 & 55.7 \\
\hline Carbamazepine & N03AF01 & 100 & 15.7 & 6280 & 62.8 \\
\hline Total & & 250 & 83.5 & 14570 & 118.5 \\
\hline \multicolumn{6}{|c|}{ Anxiolytics /sedative hypnotics } \\
\hline Lorazepam & N05BA06 & 250 & 01 & 16.6 & 0.06 \\
\hline Diazepam & N05BA01 & 10 & 71.5 & 329 & 32.9 \\
\hline Clonazepam & N03AE01 & 08 & 1.4 & 5.7 & 0.7 \\
\hline Nitrazepam & N05CD02 & 05 & 6.3 & 250 & 50 \\
\hline Propranolol & C07AA05 & 16 & 7.3 & 537 & 33.6 \\
\hline Total & & 289 & 87.5 & 1138.3 & 117.2 \\
\hline
\end{tabular}

\section{Cost analysis}

The total costs spend on the psychotropic drugs was ₹42064.44. The total cost borne by hospital was ₹34508.44 and those borne by the patients were ₹7556. The average cost of the psychotropic drugs per prescription was ₹ 168.2.

\section{Adverse drug reactions}

The total number of adverse drug reactions observed was 20(8\%). The ADR's were seen equally between the males and females. There were 9 different types of ADR's. The most common system affected was central nervous system. 
Antipsychotics (18 ADR's or 90\% of the total ADR's) were the most common class of psychotropic drugs causing ADR's.

Table 5: Pattern of ADR's.

\begin{tabular}{|ll|}
\hline ADR & Number $(\%)(\mathbf{n = 2 0})$ \\
\hline EPS & $07(35)$ \\
\hline Drowsiness/ sedation & $04(20)$ \\
\hline Ataxia/diplopia & $01(05)$ \\
\hline Postural hypotension & $02(10)$ \\
\hline Sialorrhoea & $02(10)$ \\
\hline Slurred speech & $01(05)$ \\
\hline Dryness of mouth & $01(05)$ \\
\hline Constipation & $01(05)$ \\
\hline Weight gain & $01(05)$ \\
\hline
\end{tabular}

Olanzapine (8 ADR's or $40 \%$ of the total ADR's) was the most common antipsychotic drug suspected of causing ADR's followed by trifluoperazine (7 ADR's or 35\% of the total ADR's), clozapine and trifluoperazine and trihexiphenidyl combinations (2 ADR's or $10 \%$ of total ADR's each).

Extrapyramidal syndromes were the most common ADR's followed by drowsiness and sedation (Table 5).

The causality assessment showed $50 \%$ of the ADR's were of probable type and $50 \%$ were possible type as per the Naranjo's causality assessment scale. As per the Hartwig's severity scale $9(45 \%)$ of the ADR's were mild type, $9(45 \%)$ were of moderate type and $2(10 \%)$ were severe type which included 2 extrapyramidal symptoms which prolonged the duration of hospitalization. As per the modified Schumock and Thornton preventability scale $100 \%$ of the ADR's were probably preventable.

\section{DISCUSSION}

Analysis of prescription pattern and adverse drug reactions forms a major tool for assessing the quality and safety of patients accorded in a healthcare system. Patients admitted to the psychiatry wards are resistant to treatment and severe cases do not respond to the standard drug therapy, or require multiple drugs for controlling their symptoms. Data regarding prescription patterns and adverse drug reactions in psychiatric inpatients is sparse in the field of psychopharmacology, hence this study was undertaken to document the prescription pattern and adverse drug reactions of drug therapy in psychiatric inpatients.

In present study period, we assessed prescriptions of 250 patients. Schizophrenia was the most common disorder which needed hospital admission. Depression and anxiety were found to be less in number because these disorders are treated mostly in the outpatient setting in our hospital. Our finding was in contrast to the findings of Thomspson et al. which found depression and anxiety to be the most common reason for hospitalization. ${ }^{7}$
Majority of the patients were prescribed antipsychotics across all diagnostic categories. Since present study sample consisted of large number of patients of schizophrenia, it is obvious that antipsychotics drugs were used more frequently. The average number of drugs prescribed per patient was 4.6.

The typical antipsychotics were preferred over atypical ones. In 2009 the American Psychiatric Association (APA) acknowledged the fact that the distinction between firstand second-generation antipsychotics appear to have limited clinical utility and suggested that there it is no longer imperative to prescribe an "atypical" agent as first line treatment. Olanzapine was prescribed more commonly because it was made available from the hospital pharmacy and has a good safety profile. ${ }^{8}$

Antianxiety/sedative hypnotics were used for various disorders as a co-prescription. Anti-anxiety is very useful and efficacious in wide range of conditions for short term or intermittent use. However, with long-term use the ADR's outweigh the benefits, which should be minimized by rational prescribing.

Sodium valproate was preferred over other mood stabilizers because of its better safety profile. Since TCAs were available at the hospital pharmacy it was preferred antidepressants.

The ATC classification system divides drugs into different groups according to the organ or system on which they act and their chemical, pharmacological, and therapeutic properties. The DDD was developed to overcome objections against traditional units of measurement of drug consumption and to ensure comparability between different drug utilization studies. ${ }^{9}$

The total DDD/100 bed days were 669 . The DDD/100 bed days for antipsychotics showed good consumption as compared to other studies, however for anxiolytics it was lower as compared to earlier studies..$^{10,11}$

The PDD/DDD ratio for all the psychotropic drugs were $>1$ which indicate adequate dosing of psychotropic drugs except for lorazepam and clonazepam which have $\mathrm{PDD} / \mathrm{DDD}$ ratio $<1$ which indicate under dosing of these drugs.

The cost borne by the hospital was more than the cost borne by the patient. Cost of therapy is an important factor in various psychiatric disorders, because of the prolonged treatment. Since a large percentage of drugs were prescribed from the hospital pharmacy, this helps improve compliance, especially in the low socioeconomic settings like ours. ${ }^{8}$

The number of ADR's reported were less as compared to the study conducted by Harichandran et al. Less number of ADR's in present study could be due to the fact that the spontaneous reporting was done, and patient did not report 
the ADR's which were transient and not troublesome to them. Also, only basic laboratory investigations were done due to which many ADR went unnoticed. ${ }^{12}$

EPS (35\%) was the most common ADR followed by drowsiness and sedation (20\%). Olanzapine was prescribed to large number of patients hence number of ADR's reported were also more with Olanzapine. Similar findings were reported by Harichandran et al and Prajapati et al. ${ }^{12,13}$

The Naranjo causality assessment scale showed $50 \%$ of the ADR's to be of probable type and $50 \%$ of possible type. The possible and probable causal association of the drugs is due to the fact that many drugs were administered concomitantly which have similar ADR's profile. Also, rechallenge was not attempted by the consultant psychiatrist, once a drug was withdrawn. Hence no single drug could be pointed out clearly as the cause of the particular ADR. Study conducted by Prajapati et al. and Sridhar et al. had shown maximum ADR's of probable and possible type respectively. ${ }^{12,14}$

Anticholinergic (trihexyphenidyl) was prescribed with the typical antipsychotic (trifluoperazine) as a fixed dose combination in many cases. Also, trihexyphenidyl was concomitantly prescribed whenever haloperidol was used. This decreased the number of EPS and other cholinergic side effects which are severe in nature and associated with the typical antipsychotic drugs. Since therapeutic drug monitoring is not done in our hospital all the reactions were categorized as probably preventable.

\section{CONCLUSION}

In present study prescription practices showed high percentage of polypharmacy which is predominantly because of refractory nature of psychiatric disorders among indoor patients. However, treatment is based on clinical experience and in accordance with various treatment guidelines. Thus, polypharmacy is rational. Certain precautions like prescription of anticholinergics with typical antipsychotics, limiting the use of lithium were seen to be adopted by the psychiatrics to decrease ADR's. In conclusion, it has been found that the psychotropic drugs used in psychiatry department of our tertiary care hospital is in conformity with the rational use of drugs which is based on clinical knowledge, expertise and the guidelines available in the field of psychiatric practice.

\section{ACKNOWLEDGEMENTS}

Authors would like to thank the head and, all the nursing staff of psychiatric department of government medical college, Latur and most importantly the patients who helped them in this research.

Funding: No funding sources Conflict of interest: None declared
Ethical approval: The study was approved by the Institutional Ethics Committee

\section{REFERENCES}

1. WHO. The world health report 2001-Mental health new understanding, new hope, 2001. Available at: http// www.who.int/whr/2001/en/. Accssed 12 August 2016.

2. Sachdeva PD, Patel BG. Drug utilization studiesscope and future perspectives. Int J Pharma Bio Res. 2010;1(1):11-7.

3. Dutta S, Atif BM, Kaul V, Dutta S, Dhasmana DC. Psychotropic drug utilization study in psychiatric OPD of a tertiary care teaching hospital in Dehradun, Uttarakhand. J Adv Res Bio Sci. 2013;5(4):386-91.

4. Sharma T, Vishwakarma K, Dhasmana DC, Gupta R. Adverse drug reaction monitoring in psychiatry outpatient department of a tertiary care teaching hospital. JK sci. 2014;16(4):156-60.

5. Patel MK, Barvaliya MJ, Patel TK, Tripathi CB. Drug utilization pattern in critical care unit in a tertiary care teaching hospital in India. Int J Crit Illn Inj Sci. 2013;3(4):250-5.

6. Mohanta GP. Assessment of adverse event report. In: Mohanta GP, Manna PK, eds. Textbook of Pharmacovigilance Concept and Practice. $1^{\text {st }}$ Edition. Hyderabad Pharma Med Press; 2016:29-55.

7. Thompson A, Shaw M, Harrison G, Verne J, Davidson HO, Gunnell D. Patterns of hospital admission for adult psychiatric illness in England: analysis of Hospital Episode Statistics data. B J Psych. 2004;185:334-41.

8. World Health Organisation, 2003. Introduction to drug utilization research, 2003. Available at: http//www.apps.who.int/medicinedocs/en/d/Js4876e/. Accssed 12 August 2016.

9. Thakkar KB, Jain MM, Billa G, Joshi A, Khobragade AA. A drug utilization study of psychotropic drugs prescribed in the psychiatry outpatient department of a tertiary care hospital. J Clin Diagn Res. 2013;7(12):2759-64.

10. Srinivasan R, Ramya G. Adverse drug reactioncausality assessment. Int $\mathrm{J}$ Res Pharm Chem. 2011;1(3):606-12.

11. Joel JJ, Shastry CS, Rao S. Evaluation of antipsychotic drug prescriptions in hospitalized schizophrenic patients. Int J Pharma Res Bio-Sci. 2015;4(1):353-63.

12. Mittal N, Mittal R, Singh I, Shafiq N, Malhotra S. Drug Utilization Study in a Tertiary Care Center: Recommendations for Improving Hospital Drug Dispensing Policies. Indian J Pharm Sci. 2014;76(4):308-14.

13. Harichandran DT, Viswanathan MT, Gangadhar R. Adverse drug reactions among hospitalized patients in Psychiatry Department in a Tertiary Care Hospital. J Health Res Rev. 2016;3(2):77-80.

14. Prajapati HK, Joshi ND, Trivedi HR, Parmar MC, Jadav SP. Adverse Drug Reaction Monitoring in 
Psychiatric Outpatient Department of a Tertiary Care Hospital. Natl J Integr Res Med. 2013;4(2):102-6.

15. Sridhar SB, Faris SS, Jabbar TR. Monitoring of adverse drug reactions in psychiatry outpatient department of a Secondary Care Hospital of Ras Al Khaimah, UAE. J Basic Clin Pharma. 2016;7(3):80-6.
Cite this article as: Gurung A, Jaju JB, Pawar GR, Dharmadhikari SC, Solunke RR. Study of drug utilization pattern and adverse drug reactions of psychotropic drugs in psychiatric inpatient department of tertiary care hospital. Int J Basic Clin Pharmacol 2018;7:259-65. 